\title{
Novel laparo-endoscopic hybrid procedure to treat a disconnected Roux limb after bariatric surgery
}

Obesity is a worldwide pandemic and bariatric surgery is the most effective treatment modality. Despite its satisfactory clinical results, some patients regain some of their lost weight [1,2]. Traditionally, revisional surgery to reduce the gastrojejunal anastomosis (GJA) is offered to these patients. However, revisional procedures carry a higher complication rate than primary bariatric surgeries, including fistulas and dehiscence with incidences ranging from $1 \%$ to $8.3 \%$ after laparoscopic Roux-en-Y gastric bypass (RYGB) [2-4]. The diagnosis and treatment of bariatric surgery leaks are challenging due to nonspecific clinical and laboratory findings. Some cases are associated with situations of extreme gravity, narrowing the options for treatment and thus making the complications challenging to solve [5].
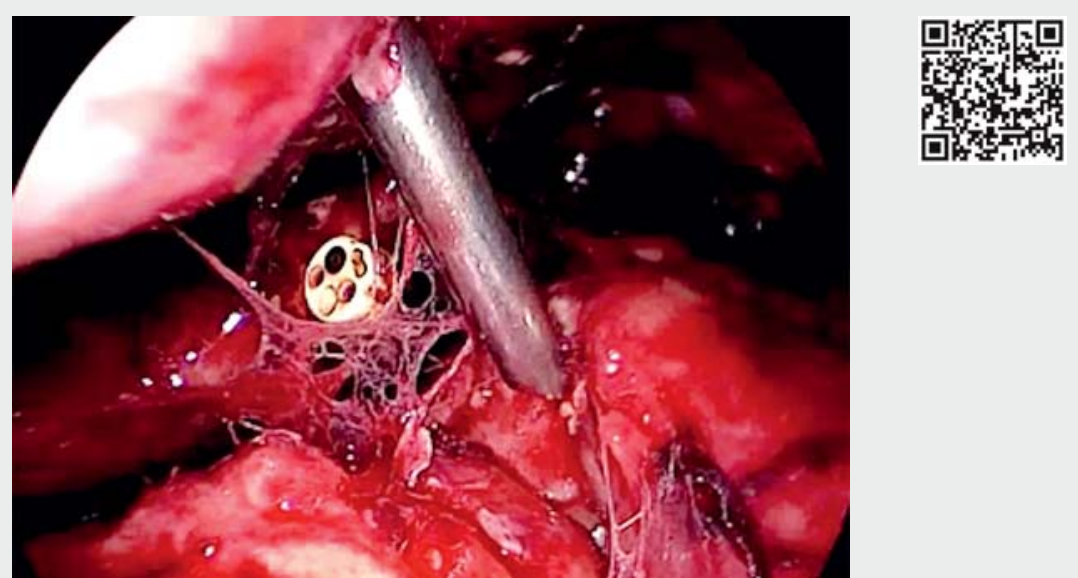

Video 1 Novel laparo-endoscopic hybrid procedure to treat a disconnected Roux limb after bariatric surgery.
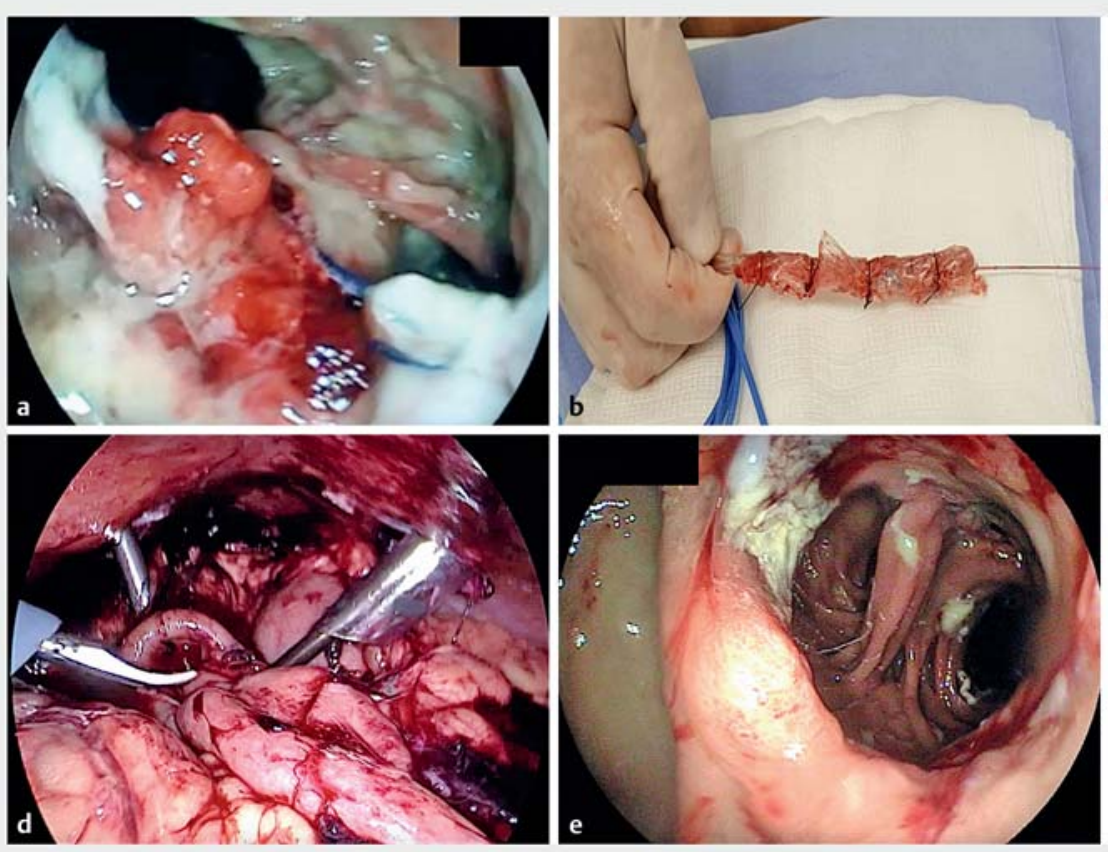

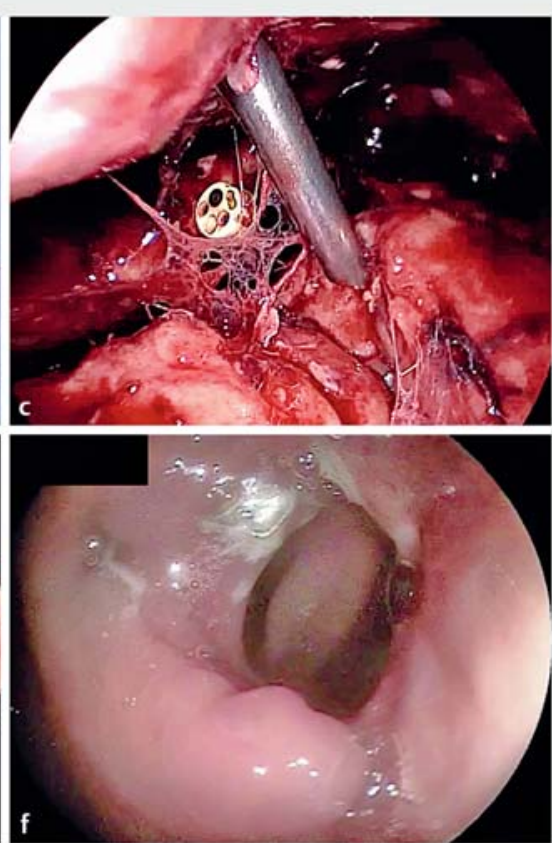

- Fig. 1 Laparo-endoscopic hybrid procedure to treat a disconnected Roux limb after bariatric surgery. a Endoscopic view of the gastrojejunal anastomosis (GJA) dehiscence and a cavity with necrotic tissue. b Modified endoscopic vacuum therapy system. $\mathbf{c}$ Laparoscopic view of the pouch and GJA disconnection showing the gastroscope tip. $\mathbf{d}$ Laparoscopic visualization of the distal portion of the FCSEMS. e Endoscopic view of the GJA after stent removal. $f$ Follow-up endoscopy 1 month later, showing the GJA. 
To illustrate this, we describe an unusual case involving a dehiscence of the gastric pouch from the Roux limb, which required prolonged intensive care and was ultimately treated by a laparo-endoscopic hybrid procedure ( $\downarrow$ Video 1 ).

A 29-year-old man, with a history of weight regain after RYGB 10 years previously $(129 \mathrm{~kg})$, underwent revisional RYGB surgery $(154 \mathrm{~kg})$. He presented 5 days later with intense abdominal pain. A computed tomography scan demonstrated a pneumoperitoneum and the patient was referred to the endoscopy unit for evaluation.

The endoscopy showed complete dehiscence of the gastric pouch from the Roux limb. A large amount of necrotic tissue was visualized and the entrance from the jejunal limb could not be identified ( Fig.1a). Endoscopic vacuum therapy was performed ( $\triangleright$ Fig. 1 b). After 4 days, a fully covered self-expandable metal stent (FCSEMS) was placed to reconnect the pouch and the GJA, under laparo-endoscopic guidance ( $\triangleright$ Fig. $\mathbf{1}$ c, d).

After 4 weeks, the FCSEMS was removed and the pouch and the GJA were con-

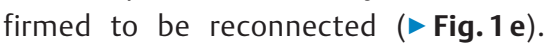
The patient was discharged on a regular diet. At follow-up endoscopy 1 month later, normal RYGB anatomy was seen (॰ Fig.1f).

Endoscopy_UCTN_Code_CPL_1AM_2AI
Competing interests

Dr. Thompson has received consultancy fees from Boston Scientific and Medtronic, and consultancy fees and institutional grants from USGIMedical, Olympus, and Apollo Endosurgery; he also has a patent issued for Endoscopic Fistula Repair, held by Brigham and Women's Hospital. Dr. Galvao Neto has received consultancy fees from Apollo Endosurgery.

The authors

Newton Teixeira dos Santos ${ }^{1}$, Diogo Turiani Hourneaux De Moura², Manoel Galvão Neto ${ }^{3}$, Flaubert Sena de Medeiros ${ }^{4}$, Mário Victor Faria Nogueira ${ }^{5}$, Christopher C. Thompson ${ }^{2}$

1 Newton Teixeira Gastroenterologia, Rio de Janeiro, Brazil

2 Division of Gastroenterology, Hepatology and Endoscopy - Brigham and Women's Hospital - Harvard Medical School, Boston, Massachusetts, United States

3 Endovitta Institute, São Paulo, Brazil and Florida International University, Florida, United States

4 Hospital Universitário Onofre Lopes Universidade Federal do Rio Grande do Norte

5 Grupo de apoio e tratamento da obesidade (GATO), Rio de Janeiro, Brazil

Corresponding author

\section{Christopher C. Thompson, MD, MS}

Division of Gastroenterology, Hepatology and Endoscopy, Brigham and Women's Hospital, 75 Francis St., Thorn 1404, Boston, MA 02115, United States

Fax: +1-617-264-6342

cthompson@hms.harvard.edu

\section{References}

[1] Schulman AR, Thompson CC. Complications of bariatric surgery: what you can expect to see in your Gl practice. Am J Gastroenterol 2017; 112: 1640 - 1655

[2] Brunaldi VO, Jirapinyo P, de Moura DTH et al. Endoscopic treatment of weight regain following Roux-en-Y gastric bypass: a systematic review and meta-analysis. Obes Surg 2018; 28: $266-276$

[3] Kuzminov A, Palmer A], Wilkinson S et al. Re-operations after secondary bariatric surgery: a systematic review. Obes Surg 2016; 26: $2237-2247$

[4] Okazaki O, Bernardo WM, Brunaldi VO et al. Efficacy and safety of stents in the treatment of fistula after bariatric surgery: a systematic review and meta-analysis. Obes Surg 2018; 28: $1788-1796$

[5] de Moura EG, Galvão-Neto MP, Ramos AC et al. Extreme bariatric endoscopy: stenting to reconnect the pouch to the gastrojejunostomy after a Roux-en-Y gastric bypass. Surg Endosc 2012; 26: 1481 - 1484

\section{Bibliography}

DOI https://doi.org/10.1055/a-0885-9095

Published online: 7.6.2019

Endoscopy 2019; 51: E341-E342

(c) Georg Thieme Verlag KG

Stuttgart · New York

ISSN 0013-726X

ENDOSCOPY E-VIDEOS
https://eref.thieme.de/e-videos
techniques in gastroenterological
endoscopy. All papers include a high
quality video and all contributions are
freely accessible online.
This section has its own submission
website at
https://mc.manuscriptcentral.com/e-videos

